\title{
Lymphoscintigraphy in Tumors of the Head and Neck Using Double Tracer Technique
}

Susanne Klutmann, Karl H. Bohuslavizki, Winfried Brenner, Steffen Höft, Sabine Kröger, Jochen A. Werner, Eberhard Henze and Malte Clausen

Department of Nuclear Medicine, University Hospital Eppendorf, Hamburg; Clinics of Nuclear Medicine and Otorhinolaryngology, Head and Neck Surgery, Christian-Albrechts-University, Kiel; Clinic of Otorhinolaryngology, Philipps University, Marburg, Germany

Knowledge of possible lymphatic drainage may facilitate planning of surgery for patients with head and neck tumors. Therefore, the aim of this study was to present a method of lymphoscintigraphy with special attention to an accurate correlation of lymphatic drainage to anatomic regions. Methods: Lymphoscintigraphy was performed using a double tracer technique before surgery in a total of 75 patients with squamous cell carcinoma of the head and neck. All patients received $100 \mathrm{MBq}{ }^{89 m} \mathrm{TC}$-colloid at three to four peritumoral sites. A perchlorate solution $(2 \mathrm{~mL})$ was given orally to block salivary glands and the thyroid gland.

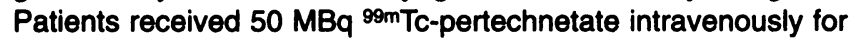
body contouring $20 \mathrm{~min}$ postinjection. Planar images were obtained over $5 \mathrm{~min}$ each, at $30 \mathrm{~min}$ and $4 \mathrm{~h}$ postinjection from anterior, right lateral and left lateral views with a large-field-ofview gamma camera. Lymphatic drainage was assessed by visual inspection and assigned to six cervical compartments. Results: Neither the salivary glands nor the thyroid gland were seen in any of the patients. In 22 of 75 patients $(29.3 \%)$, the injection site was the only focal tracer uptake seen. In contrast, lymphatic drainage was identified in the remaining 53 patients $(70.7 \%)$, and lymph nodes could be assigned easily to the six cervical compartments. Of 75 patients, $36(48 \%)$ exhibited ipsilateral lymphatic drainage. In addition, 17 patients $(22.7 \%)$ with unilateral tumor showed bilateral $(n=12)$, contralateral $(n=$ 2) or retropharyngeal $(n=3)$ lymphatic drainage. In 3 of these 17 patients, bilateral lymph node metastases were proven. A subgroup of 12 patients (16\%) exhibited N2c nodal status, despite a unilateral localized primary tumor. In 3 of these 12 patients, surgery was extended as a result of scintigraphic findings from unilateral toward bilateral neck dissection, and histology confirmed nodal involvement in these patients. Conclusion: Lymphoscintigraphy using the double tracer technique allows an accurate correlation of lymphatic drainage to the six cervical compartments. This may provide the basis for a re-evaluation of its impact in treatment planning of patients with head and neck tumors.

Key Words: lymphoscintigraphy; ${ }^{99 m}$ Tc-colloid; ${ }^{99 m}$ TC-pertechnetate; body contouring; head and neck tumors

J Nucl Mod 1999; 40:776-782

Received Jun. 2, 1998; revision accepted Oct. 18, 1998.

For correspondence or reprints contact: Karl H. Bohuslavizki, MD, Department of Nuclear Medicine, University Hospital Eppendorf, Martinistr. 52. D-20246 Hamburg, Germany.
$\mathbf{L}$ ymphoscintigraphy is a well-established tool for the support in planning of surgery for patients with malignant melanoma $(1-6)$. Visualizing both the sentinel lymph node and possible aberrant lymphatic drainage provides the surgeon with additional information about possible routes of lymphatic metastases (6-9); thus, significantly prolonging life expectancy of the patients.

In the staging of head and neck cancer, lymphoscintigraphy has been used since the early 1960 s to localize lymphatic metastases (10-20), but the results have not been convincing (13-17,21). Moreover, morphologically oriented imaging, e.g., sonography, CT and MRI, proved to be more accurate in detecting lymph node metastases in patients with head and neck malignancies (22-24). However, morphologic imaging modalities predominantly define lymph node involvement in terms of abnormal size, i.e., lymph nodes with a diameter of more than $1 \mathrm{~cm}$. However, even normal-sized lymph nodes may be infiltrated with tumor cells.

With the increasing impact of highly sophisticated procedures of neck dissection (25-28), functional imaging with lymphoscintigraphy may be of additional clinical value by showing aberrant lymphatic drainage. The knowledge of possible lymphatic drainage may support surgical treatment planning for patients with head and neck cancer. However, an accurate correlation of lymphatic drainage to anatomic regions is essential in this context. By using conventional lymphoscintigraphy, an accurate localization of lymphatic drainage is difficult, because focal tracer accumulation is displayed without any anatomic reference.

Thus, the aim of this study was to introduce a method of lymphoscintigraphy that used a double tracer technique to enable an accurate correlation of lymphatic drainage to cervical compartments.

\section{MATERIALS AND METHODS \\ Patients}

Seventy-five patients ( 7 women, 68 men; age range 40-92 y) with primary diagnoses of squamous cell carcinoma of the head and neck region were investigated. Diagnosis was established preoperatively by clinical examination, morphologic imaging, i.e., 
sonography, CT and MRI, and biopsy specimens. Before surgery, patients were submitted consecutively without any preselection for lymphoscintigraphy. Patients were treated surgically according to conventional therapeutic procedures. Postoperatively, tumor, node and metastasis (TNM) classification was applied according to the 1987 guidelines of the Union Internationale Contre le Cancer (UICC). The nodal status of the tumors as defined by histopathology is given in detail in Table 1 .

\section{Lymphoscintigraphy}

Lymphoscintigraphy was performed using a double tracer technique. First, all patients received $100 \mathrm{MBq}{ }^{99 m} \mathrm{Tc}$ colloid (Solco Nanocoll; Solco, Basel, Switzerland). The particle size of the colloid was $<80 \mathrm{~nm}$ in diameter. ${ }^{99} \mathrm{mTc}$-colloid was dissolved in $0.1-0.2 \mathrm{~mL}$ physiological saline and then injected in three to four peritumoral sites. Second, $2 \mathrm{~mL}$ perchlorate solution was given orally to block both salivary glands and the thyroid gland. Third, patients received $50 \mathrm{MBq}{ }^{99 \mathrm{~m} T c}$-pertechnetate intravenously for body contouring $20 \mathrm{~min}$ postinjection. Planar images were obtained over $5 \mathrm{~min}$ at $30 \mathrm{~min}$ and $4 \mathrm{~h}$ postinjection from anterior, right lateral and left lateral views with a largefield-of-view gamma camera equipped with a low-energy allpurpose collimator (Gamma Diagnost Tomo; Philips, Hamburg, Germany).

\section{Assessment of Lymphatic Drainage}

Lymphatic drainage was assessed by visual inspection and correlation of lymphatic drainage to the six cervical lymph node compartments (25), as shown in Figure 1. Compartment I is located between the body of the mandible, the posterior belly of the contralateral digastric muscle and the ipsilateral digastric muscle. Compartments II to IV are spread along the region of the deep jugular lymph nodes. The skull base and the carotid bifurcation define the boundaries of compartment II. Compartment III reaches from the carotid bifurcation to the intersection of the omohyoid muscle with the internal jugular vein. Compartment IV is situated caudally from compartment III, limited by the clavicle. Compartment $\mathrm{V}$ contains all lymph nodes of the posterior triangle. The trapezius muscle, the sternocleidomastoid muscle and the clavicle mark its boundaries. Compartment VI is extended from the hyoid bone to the jugulum and limited laterally by the right and left common carotid artery.

TABLE 1

Lymphatic Drainage in 75 Patients Correlated to Nodal Status

\begin{tabular}{lcccccc}
\hline No & & & & & \\
$\begin{array}{c}\text { Nodal } \\
\text { status }\end{array}$ & $\begin{array}{c}\text { lymphatic } \\
\text { drainage }\end{array}$ & lpsilateral & Bilateral & $\begin{array}{c}\text { Contra- } \\
\text { lateral }\end{array}$ & $\begin{array}{c}\text { Retro- } \\
\text { pharyngeal }\end{array}$ & Total \\
\hline N0 & 14 & 19 & 7 & 0 & 1 & 41 \\
N1 & 4 & 4 & 2 & 0 & 0 & 10 \\
N2a & 1 & 0 & 1 & 0 & 0 & 2 \\
N2b & 1 & 5 & 1 & 1 & 1 & 9 \\
N2c & 2 & 7 & 1 & 1 & 1 & 12 \\
N3 & 0 & 1 & 0 & 0 & 0 & 1 \\
\hline Total & 22 & 36 & 12 & 2 & 3 & 75
\end{tabular}

Nodal status assigned according to 1987 guidelines of the Union Internationale Contre le Cancer.

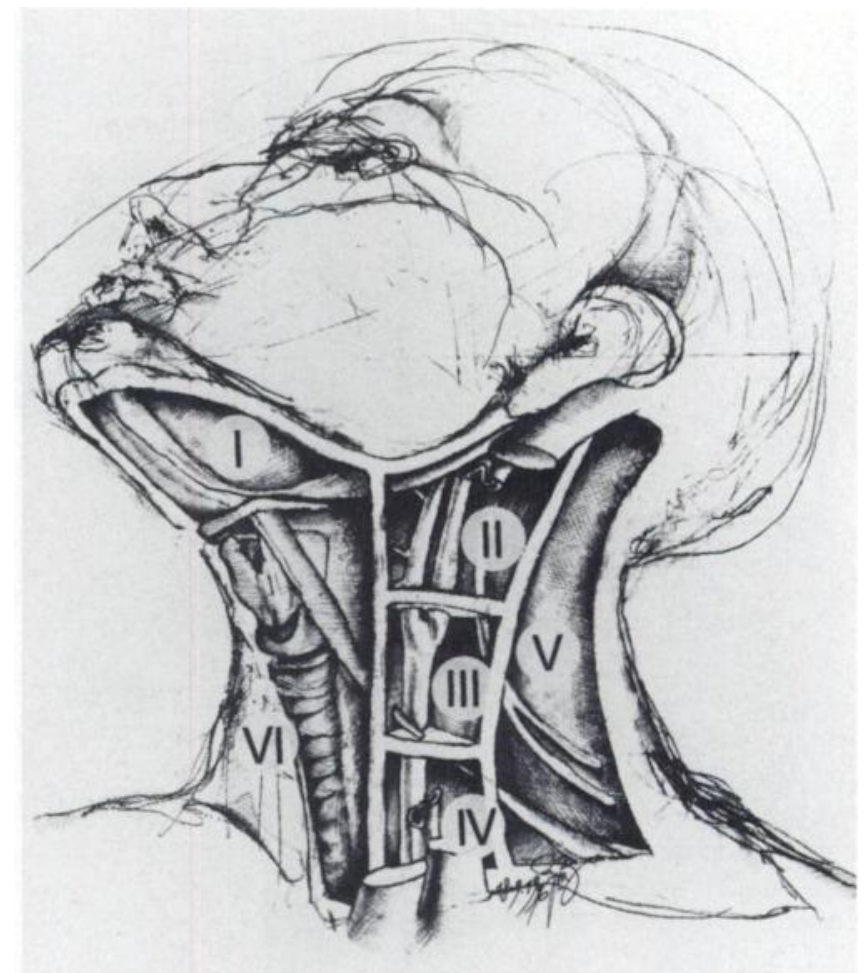

FIGURE 1. Schematic outline of cervical compartments.

\section{RESULTS}

Neither the salivary glands nor the thyroid gland were seen in any of the patients.

In 22 of 75 patients (29.3\%), the injection site was the only focal tracer accumulation seen; thus, no lymphatic drainage could be demonstrated at all (Fig. 2). In 14 of these 22 patients, N0 nodal status was confirmed by histopathology; 6 patients exhibited ipsilateral lymphatic metastases $(\mathrm{N} 1=4, \mathrm{~N} 2 \mathrm{a}=1, \mathrm{~N} 2 \mathrm{~b}=1)$; and the remaining 2 patients, without any lymphatic drainage as defined by lymphoscintigraphy, exhibited lymph node metastases on both sides of the neck, i.e., N2c nodal status as defined by histopathology (Table 1).

In contrast, lymphatic drainage could be observed by lymphoscintigraphy in 53 of 75 patients (70.7\%). In all 53 patients, lymph nodes could be assigned easily to the six cervical lymph node compartments as a result of appropriate body contouring. Details of these patients and the respective lymphatic drainage are given in Table 2.

Although 36 of 75 patients (48\%) showed ipsilateral lymphatic drainage (Fig. 3), 12 of 75 patients (16\%) exhibited bilateral lymphatic drainage (Fig. 4). In addition, lymphoscintigraphy revealed lymph nodes at the tumorcontralateral side in 2 of 75 patients $(2.7 \%)$, whereas lymphatic drainage was not detectable at the tumoripsilateral side of the neck. Retropharyngeal lymphatic drainage could be shown in 3 of 75 patients (4\%). Thus, in our patient population, 17 of 75 patients $(22.7 \%)$ revealed an unexpected lymphatic drainage to the contralateral side of the neck $(n=2)$, at retropharyngeal sites $(n=3)$ or to both 


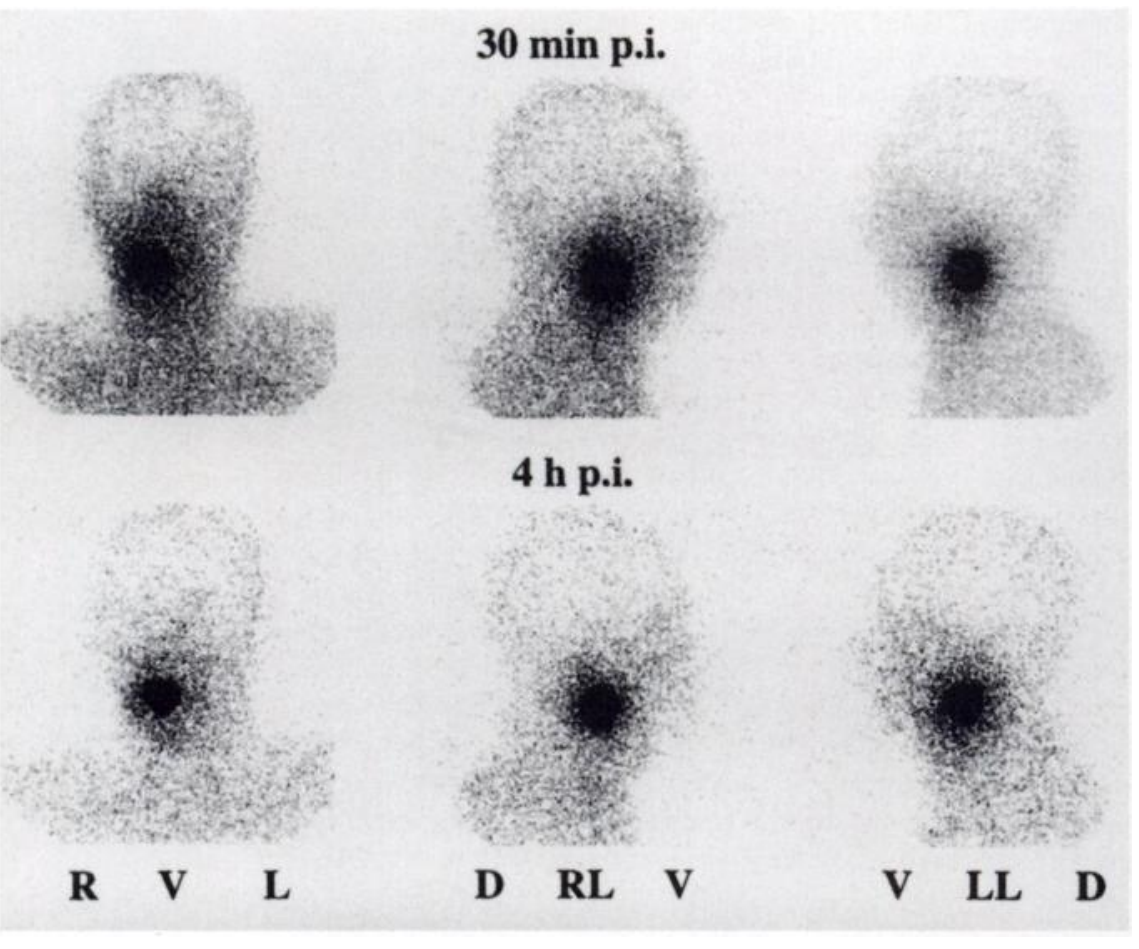

FIGURE 2. Planar images from anterior ( $R$ V L), right lateral (D RL V) and left lateral (V LLD) views, $30 \mathrm{~min}$ and $4 \mathrm{~h}$ postinjection (p.i.) of 57-y-old patient with carcinoma of right hypopharynx. Injection site is only focal tracer accumulation seen. No lymphatic drainage was observed.

sides of the neck $(n=12)$. Eight of these patients had a N0 nodal status, whereas 6 patients showed ipsilateral nodal metastases only $(\mathrm{N} 1=2, \mathrm{~N} 2 \mathrm{a}=1, \mathrm{~N} 2 \mathrm{~b}=3)$. Three patients with aberrant lymphatic drainage had lymph node metastases on both sides of the neck, i.e., N2c nodal status (Table 1).

A subgroup of 12 patients (16\%) exhibited N2c nodal status. Thus, 12 patients had lymphatic metastasis of both sides of the neck, although the primary tumor was localized unilaterally. Of these 12 patients, 2 showed no lymphatic drainage, whereas 7 patients revealed ipsilateral scintigraphic findings. In 3 patients with an aberrant lymphatic drainage observed preoperatively (bilateral $=1$, contralateral $=1$, retropharyngeal $=1$ ), surgery was extended as a result of scintigraphic findings from unilateral toward bilateral neck dissection, and nodal involvement was confirmed by histology in all these patients. Thus, lymphoscintigraphy performed preoperatively revealed aberrant lymphatic drainage in $25 \%$ of all patients with bilateral lymphatic metastases.

\section{DISCUSSION}

Standard treatment of malignant melanoma consists of wide local excision and regional lymphadenectomy of nodes in the lymphatic drainage basin. Lymphoscintigraphy has been shown to be helpful in predicting the lymphatic drainage pattern of melanoma. In the management of patients with head and neck cancer, therapeutic outcome is mainly influenced by the presence of nodal metastases (29). Although CT and MRI allow detection of abnormally enlarged nodes, neither borderline-sized nodes nor extracapsular spread can reliably be differentiated (29). This lack of accurate and reliable diagnostic methods for detecting metastatic lymph nodes is a serious shortcoming in the preoperative work-up of patients with head and neck cancer. Although micrometastases cannot be detected by lymphoscintigraphy (11), this functional imaging method may assist in delineating possible aberrant lymphatic drainage in the individual patient. This may have an impact in the planning of surgical treatment.

In this study, lymphoscintigraphy was performed preoperatively in a total of 75 patients with histologically proven squamous cell carcinoma. In 22 of these 75 patients, the peritumoral area was the only focal tracer accumulation seen. Thus, a lymphatic drainage could not be observed with lymphoscintigraphy. It is well known that a lack of scintigraphic lymphatic drainage may be caused by tumor cell embolization of afferent lymph vessels and a subsequent radiocolloid hold-up proximal to this obstruction (30). This lack of scintigraphic flow might be the reason for undetected lymph nodes in 2 patients with histologically confirmed lymph node metastases on both sides of the neck. However, even the injection technique may play a significant role both in determining lymphatic uptake of the tracer and in visualization of lymph nodes. Furthermore, lymph nodes occasionally may be absent without any pathologic reason (1). This was obviously the case in 14 of these 22 patients who finally exhibited N0 nodal status as defined by histopathology.

In contrast, lymphatic drainage could be observed in 53 of 75 patients, thereby allowing the clinician to identify potential localizations of lymphatic metastases. In our patient population, 17 of 75 patients revealed preoperatively an unexpected, aberrant lymphatic drainage to the contralat- 
TABLE 2

Demographic Data of 53 Patients with Lymphatic Drainage as Seen by Lymphoscintigraphy

\begin{tabular}{|c|c|c|c|c|c|c|c|c|c|c|c|c|c|c|c|}
\hline \multirow[b]{2}{*}{ Sex } & \multirow{2}{*}{$\begin{array}{c}\text { Age } \\
\text { (y) }\end{array}$} & \multirow[b]{2}{*}{ Stage } & & \multicolumn{5}{|c|}{ Right-sided compartments } & \multicolumn{7}{|c|}{ Left-sided compartments } \\
\hline & & & & 1 & 2 & 3 & 4 & 5 & $\overline{1}$ & 2 & 3 & 4 & 5 & 6 & Retro \\
\hline$M$ & 65 & T4N3MO & Ipsilateral & & & & & & + & & & & & & \\
\hline$M$ & 63 & T2NOMO & Ipsilateral & & + & & + & & & & & & & & \\
\hline $\mathbf{M}$ & 53 & T1NOMO & Ipsilateral & & & & & & & + & & & & & \\
\hline $\mathbf{M}$ & 66 & T1NOMO & Ipsilateral & & & + & & & & & & & & & \\
\hline$M$ & 49 & T3NOMO & Ipsilateral & + & + & + & + & & & & & & & & \\
\hline $\mathbf{M}$ & 52 & T3NOMO & Ipsilateral & & + & & & & & & & & & & \\
\hline $\mathbf{M}$ & 58 & T2NOMO & Ipsilateral & & + & & & & & & & & & & \\
\hline $\mathbf{M}$ & 45 & T2N2CMO & Ipsilateral & & & & & & & & + & & & & \\
\hline $\mathbf{M}$ & 47 & T4N2cMX & Ipsilateral & + & & & & & & & & & & & \\
\hline $\mathbf{M}$ & 53 & T4N2bMO & Ipsilateral & & + & & & & & & & & & & \\
\hline$M$ & 58 & T4N2bMO & Ipsilateral & & & & & & & & + & & & & \\
\hline$F$ & 55 & T2NOMO & Ipsilateral & & & & & & & + & + & & & & \\
\hline$M$ & 53 & T4N1MO & Ipsilateral & + & & & & & & & & & & & \\
\hline$M$ & 59 & T2NOMO & Ipsilateral & & + & & & & & & & & & & \\
\hline$M$ & 66 & T4NOMO & Ipsilateral & & + & & & & & & & & & & \\
\hline$F$ & 57 & T2N2bMO & Ipsilateral & & + & + & + & & & & & & & & \\
\hline$M$ & 57 & T2NOMO & Ipsilateral & & & & & & & + & + & + & & & \\
\hline$M$ & 74 & T1NOMO & Ipsilateral & & & & & & & + & & & & & \\
\hline$M$ & 61 & T4NOMO & Ipsilateral & & + & & & & & & & & & & \\
\hline $\mathbf{M}$ & 64 & T1N1M0 & Ipsilateral & & + & & & & & & & & & & \\
\hline $\mathbf{M}$ & 50 & T4N2cMO & Ipsilateral & & + & & & & & & & & & & \\
\hline$M$ & 79 & TINOMO & Ipsilateral & & & & & & & & & + & & & \\
\hline $\mathbf{M}$ & 47 & T4N2CMO & Ipsilateral & & & + & & & & & & & & & \\
\hline$M$ & 55 & T2NOMO & Ipsilateral & & + & & & & & & & & & & \\
\hline$M$ & 42 & T3N2CMO & Ipsilateral & & & & & & & + & & & & & \\
\hline$M$ & 50 & TINOMO & Ipsilateral & & & & & & & & & + & & & \\
\hline$M$ & 56 & T4N2CMO & Ipsilateral & & + & & & & & & & & & & \\
\hline $\mathbf{M}$ & 56 & T2N2CMO & Ipsilateral & & & & & & & + & & & & & \\
\hline $\mathbf{M}$ & 51 & T2NOMO & Ipsilateral & & + & & & & & & & & & & \\
\hline $\mathbf{M}$ & 69 & T3N2bMO & Ipsilateral & & + & + & + & & & & & & & & \\
\hline$M$ & 55 & T3N2bMO & Ipsilateral & & & & + & & & & & & & & \\
\hline$M$ & 63 & T3NOMO & Ipsilateral & & + & & & & & & & & & & \\
\hline $\mathbf{M}$ & 66 & T1NOMO & Ipsilateral & & & & & & & + & & & & & \\
\hline$M$ & 60 & T1N1M0 & Ipsilateral & & & & & & & & & & & + & \\
\hline$M$ & 54 & T2NOMO & Ipsilateral & & + & & & & & & & & & & \\
\hline$M$ & 79 & T1N1M0 & Ipsilateral & + & & & & & & & & & & & \\
\hline $\mathbf{M}$ & 68 & T3NOMO & Bilateral & & + & & & & & + & + & + & & & \\
\hline $\mathbf{M}$ & 57 & T2N1M0 & Bilateral & + & & & + & & + & & & & & & \\
\hline$M$ & 61 & T2N2CMO & Bilateral & & + & & & & & + & & & & & \\
\hline$F$ & 62 & T2NOMX & Bilateral & & + & & & & & + & & & & & \\
\hline$M$ & 54 & T2N2aMO & Bilateral & & + & + & & & & + & + & + & & & \\
\hline$M$ & 59 & T4N2bMO & Bilateral & & + & & & & & + & & & & & \\
\hline$M$ & 52 & T2NOMO & Bilateral & + & & & & & + & + & + & & & + & \\
\hline$M$ & 59 & T4NOMO & Bilateral & & + & + & + & & & + & & & & & \\
\hline $\mathbf{M}$ & 40 & T1NOMO & Bilateral & + & + & & & & + & & & & & & \\
\hline$M$ & 60 & T2NOMO & Bilateral & & + & + & + & & & + & & + & & & \\
\hline$M$ & 86 & T3N1M1 & Bilateral & & + & & + & & & & & + & & & \\
\hline $\mathbf{F}$ & 66 & T1NOMO & Bilateral & & + & & & & & + & & & & & \\
\hline$M$ & 63 & T4N2bMO & Contralateral & & & & + & & & & & & & & \\
\hline$M$ & 57 & T4N2CMO & Contralateral & & + & & & & & & & & & & \\
\hline$M$ & 49 & T4N2bMO & Retropharyngeal & & & & & & & & & & & & + \\
\hline$M$ & 43 & T3N2CMO & Retropharyngeal & & & & & & & & & & & & + \\
\hline$M$ & 76 & T1NOMO & Retropharyngeal & & & & & & & & & & & & + \\
\hline
\end{tabular}

Tumor, node and metastasis classification according to the 1987 guidelines of the Union Internationale Contre le Cancer and correlation to six cervical lymph node compartments as described in (25). 


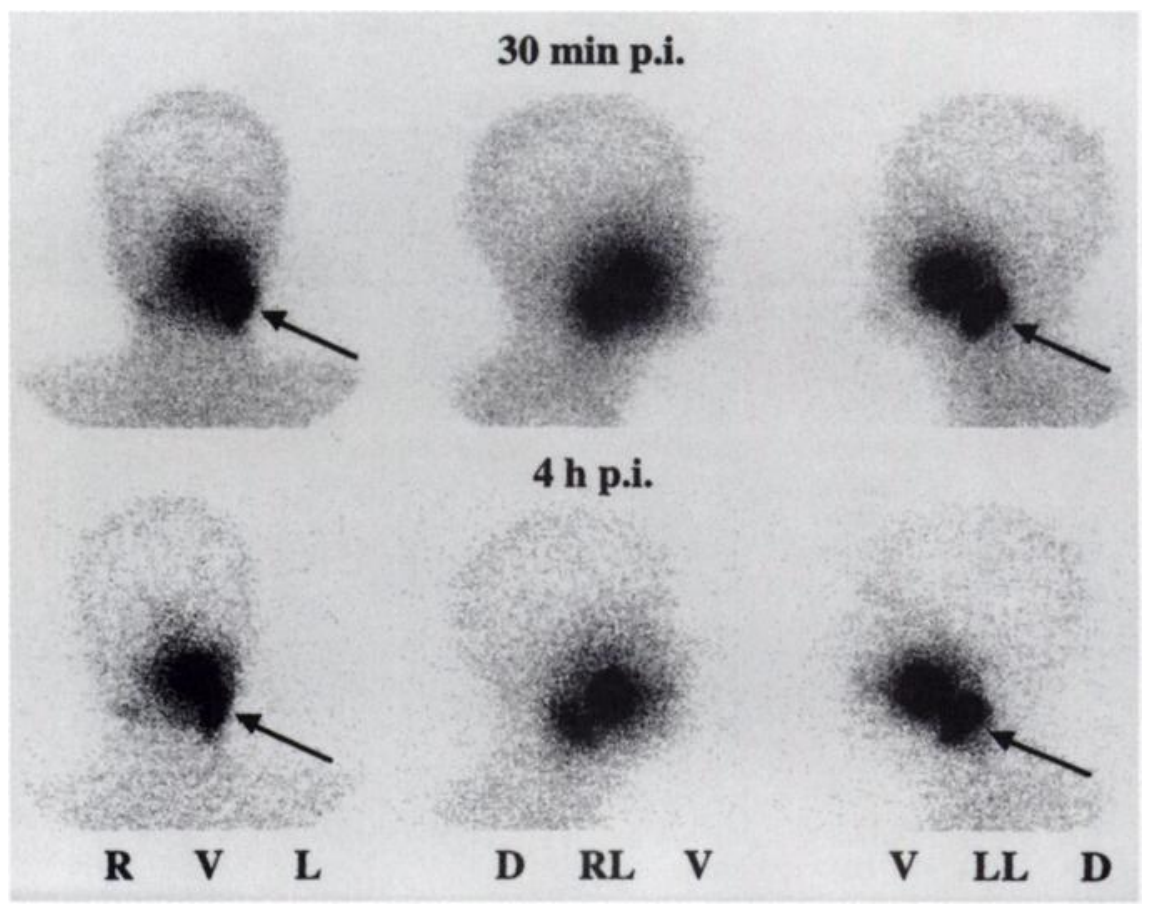

FIGURE 3. Planar images from anterior ( $R$ V L), right lateral ( $R L V$ ) and left lateral (V LLD) views, $30 \mathrm{~min}$ and $4 \mathrm{~h}$ postinjection (p.i.) of 43-y-old patient with carcinoma of left palatine arc. Ipsilateral lymphatic drainage to compartment II (arrow) was seen.

eral side of the neck, at retropharyngeal sites or at both sides of the neck. In 3 of these 17 patients, lymph nodes were histologically positive for metastatic disease. Without knowledge of the result of scintigraphy, metastatic spread was not expected by either clinical experience or standard imaging.

In 12 of 75 patients, pathologic staging revealed bilateral lymphatic metastases, although the primary tumor was localized on one side only. In $25 \%$ of these 12 patients, an aberrant lymphatic drainage was detected by preoperative lymphoscintigraphy. In fact, in these 3 patients, surgery was extended as a result of the scintigraphic findings from unilateral toward bilateral neck dissection, and histology confirmed nodal involvement. Thus, scintigraphic findings may significantly alter the extent and type of surgery. This holds especially true in modern head and neck surgery, performing a multitude of modified techniques for neck dissection procedures (25-28), i.e., radical neck dissection, modified radical neck dissection, selective neck dissection and extended radical neck dissection (31). Cervical anatomy, as well as the biologic behavior of squamous cell carcinoma

FIGURE 4. Planar images from anterior (R V L), right lateral (D RL V) and left lateral (VLLD) views, $30 \mathrm{~min}$ and $4 \mathrm{~h}$ postinjection (p.i.) of 66-y-old patient with squamous cell carcinoma of right vestibule of nose. Ipsilateral and contralateral lymphatic drainage to both compartments II (arrows) was seen.

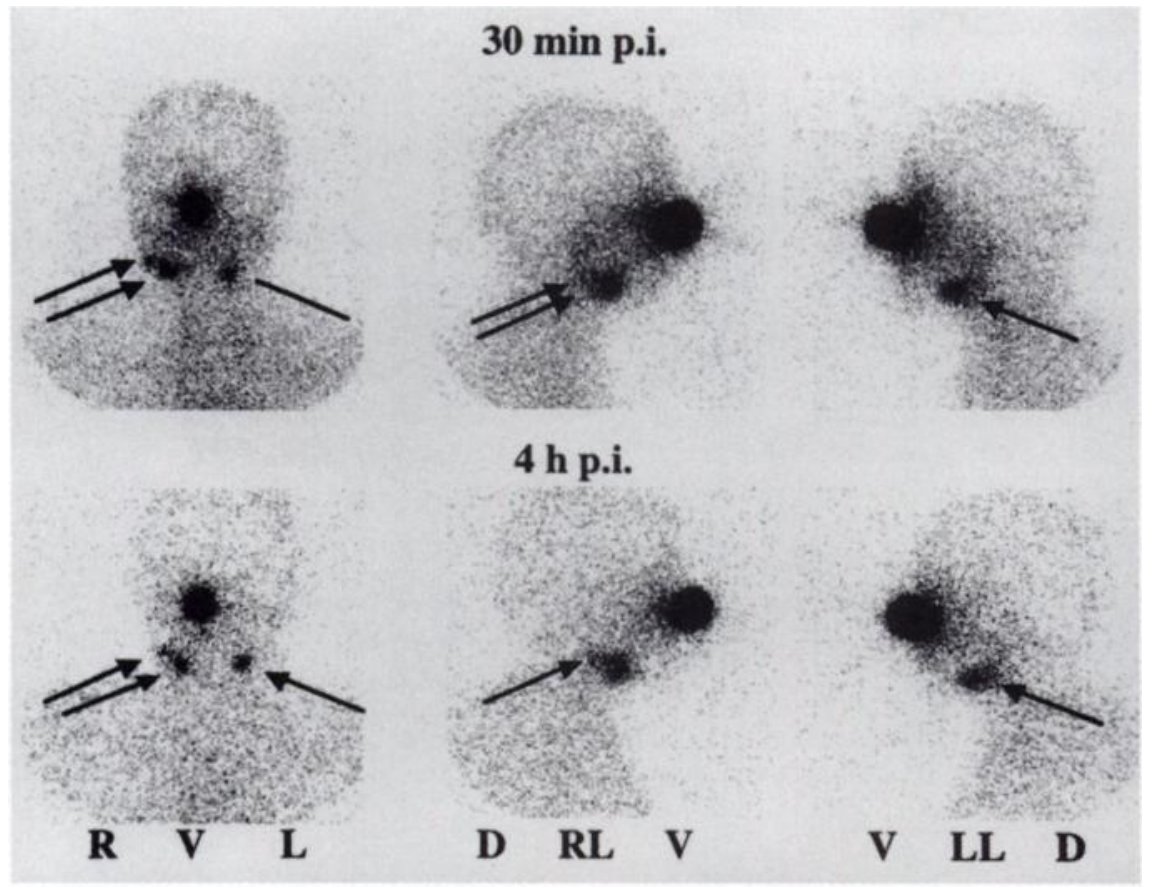


of the head and neck, should be kept in mind in treatment planning for individual patients. Both parameters significantly influence the decision whether to perform standard treatment, i.e., radical neck dissection (32), or to modify radical neck dissection toward a procedure tailor-made for an individual patient (33-35). This holds especially true for patients with a small primary cancer staged NO when treatment remains controversial (29), because of the high incidence of occult nodal metastases on the one hand and the poor outcome after salvage treatment on the other hand (36). In addition, lymphoscintigraphy may identify the sentinel lymph node, allowing an elective neck dissection so that, according to the status of the nodal disease, an appropriate therapeutic protocol may be designed for the individual patient $(19,37)$.

Lymphoscintigraphy may gain additional clinical impact under the prerequisite that lymphatic drainage can accurately be correlated to anatomic regions described (25). Various methods have been described for body contouring. The drawing of the patient's body contour after image acquisition is a simple but rather inaccurate method of anatomic landmarking. Another widely used technique of body contouring is transmission imaging $(38,39)$. To localize lymph nodes, images can be simultaneously obtained with ${ }^{58} \mathrm{Co}$ markers positioned at the sternal notch or at the chin. However, this method of body contouring is inaccurate as well. Moreover, it mainly depends on the anatomic knowledge level of the technologist performing the study. In contrast, body contouring by ${ }^{99 \mathrm{~m}} \mathrm{Tc}$-pertechnetate applied intravenously is easy to perform and allows an accurate correlation of anatomic structures to lymph drainage. In fact, in all 53 patients exhibiting lymphatic drainage, lymph nodes could be assigned easily to the six cervical compartments previously described by Werner (25). Moreover, an overlap of both the salivary glands and the thyroid gland with lymphatic structures could be avoided successfully by the application of the perchlorate solution. This provided the basis for an accurate anatomic localization of scintigraphic lymph nodes. In addition, the lack of ${ }^{99} \mathrm{~m} T c$-pertechnetate uptake into these glands increases its renal excretion and thereby decreases patients' radiation exposure (40).

\section{CONCLUSION}

Lymphoscintigraphy using a double tracer technique enables an accurate correlation of lymphatic drainage to cervical compartments. This may provide the basis to re-evaluate its impact in the treatment planning of different procedures of neck dissections in tumors of the head and neck.

\section{REFERENCES}

1. Ege GN. Lymphoscintigraphy in oncology. In: Henkin RE, Boles MA, Dillehay GL, et al., eds. Nuclear Medicine. Vol. 2. St. Louis, MO: Mosby; 1996:1504 1523.

2. Krag DN, Meijer SJ, Weaver DL, et al. Minimal-access surgery for staging of malignant melanoma. Arch Surg. 1995;130:654-660.
3. van der Veen H, Hoekstra OS, Paul MA, Cuesta MA, Meijer S. Gamma probe-guided sentinel node biopsy to select patients with melanoma for lymphadenoectomy. Br J Surg. 1994;81:1769-1770.

4. Wells KE, Cruse CW, Daniels S, Berman C, Norman J, Reintgen DS. The use of lymphoscintigraphy in melanoma of the head and neck. Plast Reconstr Surg. 1994;93:757-761.

5. Norman J Jr, Cruse W, Ruas E, et al. The expanding role of lymphoscintigraphy in the management of cutaneous melanoma. Am Surg. 1989;55:689-694.

6. Woods JE, Freedman AM, Brown ML. Lymphoscintigraphy as a guide to treatment in malignant melanoma. Ann Plast Surg. 1989;22:150-155.

7. Reintgen DS, Sullivan D, Coleman E, Briner W, Croker BP, Seigler HF. Lymphoscintigraphy for malignant melanoma. Surgical considerations. Am Surg. 1983;49:672-678.

8. Bostick P, Essner R, Sarantou T, et al. Intraoperative lymphatic mapping for early-stage melanoma of the head and neck. Am J Surg. 1997;174:536-539.

9. Alex JC, Krag DN, Harlow SP, et al. Localization of regional lymph nodes in melanomas of the head and neck. Arch Otolaryngol Head Neck Surg. 1998;124: 135-140.

10. Charron M, Mochizuki T, Levine G, Tauxe WN. Lymphoscintigraphy in the detection of cervical metastases from oral carcinoma: a pilot study. Ann $R$ Coll Surg Engl. 1992;74:436-445.

11. Hildmann H, Kosberg RD, Tiedjen KU. Lymphoscintigraphic studies of regional lymph vessels in patients with head and neck tumors. HNO. 1987;35:31-33.

12. Civantos FJ, Moffat FL, Duque C, Gulec SA. Current surgical techniques. Lymphoscintigraphy and sentinel node biopsy: a potential new approach in the management of the N0 neck. Curr Opin Otolaryngol Head Neck Surg. 1997;5:99104.

13. Schwab W, Scheer KE, zum Winkel K. Scintigraphy of the cervical lymphatic system [in German]. Arch Ohr-Nas-u Kehlk-Heilk. 1964;183:382-387.

14. Schwab W. Lymphatic drainage of radiocolloids in irradiated and nonirradiated cervical regions (scintigraphy of the cervical system) [in German]. Laryngol Rhinol Otol. 1964;43:230-234.

15. Schwab W, Scheer KE, zum Winkel K. Scintigraphy of the cervical lymphatic system after radical neck dissection [in German]. Laryngol Rhinol Otol. 1965;44: 326-330.

16. Schwab W, Scheer KE, zum Winkel K. Scintigraphy of the cervical lymphatic system after irradiation and surgical treatment [in German]. Nuklearmedizin. 1965;4:326-332.

17. Schwab W, zum Winkel K. Scintigraphy of the cervical lymphatic system: state of the art [in German]. Nuklearmedizin. 1967;6:234-249.

18. Sri-Pathmanathan $R$, Railton $R$. Lymphoscintigraphy in the detection of cervical metastases from oral carcinoma: a pilot study [letter]. Ann $R$ Coll Surg Engl. 1992;74:436.

19. Terui S, Terauchi T, Ebihara S, et al. Lymphoscintigraphy of head-and-neck cancer. Angiology. 1992;43:925-932.

20. Parell GJ, Becker GD, Simpson GT. Prediction of lymph node metastases by lymphoscintigraphy of the neck after peri-cancer injection of a radiocolloid. Otolaryngol Head Neck Surg. 1981;89:67-68.

21. Blakeslee DB, Becker GD, Simpson GT, Patten DH, Sprengelmeyer J. Lymphoscintigraphy of the neck. Otolaryngol Head Neck Surg. 1985;93:361-365.

22. Eichhorn T, Schroeder HG, Glanz H, Schwerk WB. Histologically controlled comparison of palpation and sonography in the diagnosis of cervical lymph node metastases. Laryngol Rhinol Otol. 1987;66:266-274.

23. Stern WB, Silver CE, Zeifer BA, Persky MS, Heller KS. Computed tomography of the clinically negative neck. Head Neck. 1990;12:109-113.

24. Close LG, Merkel M, Vuitch MF, Reisch J, Schaefer SD. Computed tomographic evaluation of regional lymph node involvement in cancer of the oral cavity and oropharynx. Head Neck. 1989;11:309-317.

25. Werner JA. Lymphatic drainage of malignant head and neck tumors: state of the art [in German]. Eur Arch Otorhinolaryngol. 1997;12(suppl 1):47-85.

26. McCaffrey TV. Surgical treatment in head and neck cancer. Curr Opin Oncol. 1991;3:519-522.

27. Bocca E, Pignataro O, Oldini C, Cappa C. Functional neck dissection: an evaluation and review of 843 cases. Laryngoscope. 1984;94:942-945.

28. Stell PM. The management of cervical lymph nodes in head and neck cancer. Proc $R$ Soc Med. 1975; 68:83-85.

29. Anzai Y, Brunberg JA, Lufkin RB. Imaging of nodal metastases in the head and neck. J Magn Reson Imaging. 1997;7:774-783.

30. Koch HF. Irregular cervical dissemination of tumours of the maxillo-facial region. J Maxillofac Surg. 1977;5:159-163.

31. Robbins KT, Medina JE, Wolfe GT, Levine PA, Sessions RB, Pruet CW. Standardizing neck dissection terminology. Official report of the Academy's Committee for Head and Neck Surgery and Oncology. Arch Otolaryngol Head Neck Surg. 1991;117:601-605. 
32. Stringer SP. Current concepts in surgical management of neck metastases from head and neck cancer. Oncology (Huntingt). 1995;9:547-554.

33. Houck JR, Medina JE. Management of cervical lymph nodes in squamous carcinomas of the head and neck. Semin Surg Oncol. 1995;11:228-239.

34. Shah JP, Andersen PE. The impact of nodal metastasis on modifications of neck dissection. Ann Surg Oncol. 1994;1:521-532.

35. Shah JP, Andersen PE. Evolving role of modifications in neck dissection for oral squamous carcinoma. Br J Oral Maxillofac Surg. 1995;33:3-8.

36. Ono I, Ebihara S, Saito H, Yoshizumi T. Correlation between prognosis and degree of lymph node involvement in carcinoma of the head and neck. Auris Nasus Larynx. 1985;12(suppl 2):S85-S89.
37. Candela FC, Kothari K, Shah JP. Patterns of cervical node metastases from squamous carcinoma of the oropharynx and hypopharynx. Head Neck. 1990;12: 197-203.

38. Mudun A, Murray DR, Herda SC, et al. Early stage melanoma: lymphoscintigraphy, reproducibility of sentinel lymph node detection, and effectiveness of the intraoperative gamma probe. Radiology. 1996;199:171-175.

39. Goldfarb LR, Alazraki NP, Eshima D, Eshima LA, Herda SC, Halker RK. Lymphoscintigraphic identification of sentinel lymph nodes: clinical evaluation of 0.22-micron filtration of Tc-99m sulfur colloid. Radiology. 1998;208:505-509.

40. Johansson L, Mattsson S, Nosslin B, Leide-Svegborn S. Effective dose from radiopharmaceuticals. Eur J Nucl Med. 1992;19:933-938. 